\title{
NUEVAS PERSPECTIVAS DE LOS ESTUDIOS CARIBEÑOS EN LA ARGENTINA (2010-2012)
}

\author{
POR \\ Francisco Aiello \\ Universidad Nacional de Mar del Plata / CONICET
}

Los estudios sobre la literatura del Caribe hispánico ostentan una tradición consolidada en la Argentina, puesto que distintos centros universitarios cuentan con investigadores o grupos de trabajo consagrados especialmente a las literaturas de Cuba y Puerto Rico. Sin embargo, las publicaciones argentinas dedicadas al Caribe han cobrado un renovado vigor durante el reciente trienio 2010-2012, según puede constatarse a través de la cuantiosa aparición de libros. ${ }^{1}$ Aun cuando los trabajos sobre la literatura caribeña escrita en lengua española continúen siendo la práctica dominante, esta concentración cuantitativa se complementa con una perspectiva que procura considerar el Caribe como conjunto - sin desconocer su heterogeneidad- $\mathrm{y}$, en relación con esto, la investigación va trazando puentes con discursos provenientes de otros bloques lingüísticos.

El corpus de esta reseña se limita a tres libros monográficos sobre autores de las Antillas hispánicas -Lecturas de la tradición en la poesía de José Lezama Lima de Daniela Chazarreta, Mapa de una pasión caribeña de Carolina Sancholuz y En nuestra quimera ardiente y querida de Gabriela Tineo-, tres volúmenes colectivos parcial o completamente dedicados al Caribe -Viaje y relato en Latinoamérica (coordinado por Mónica Marinone y Gabriela Tineo), Memorias del silencio e Ínsulas y poéticas, estos dos últimos a cargo de Graciela Salto-y un estudio comparativo que pone en diálogo dos publicaciones periódicas emblemáticas de América Latina, como son la cubana Orígenes y la argentina Sur; se trata de El diálogo oblicuo de Nancy Calomarde, cuya investigación exige que se le dedique un espacio mayor para poder dar cuenta de la particularidad

\footnotetext{
1 En esta nota nos ocupamos solamente de los libros dedicados al Caribe, aunque también se destaca la publicación de numerosos artículos en distintas revistas especializadas-Anclajes, Celehis, Katatay, Orbis Tertius etc.-, así como comunicaciones y conferencias aparecidas en actas de reuniones científicas. Sobre este punto, debe mencionarse la realización, bajo la dirección de Teresa Basile y Nancy Calomarde, del Congreso Internacional "El Caribe en sus Literaturas y Culturas", que se celebró en la ciudad de Córdoba del 1 al 3 de septiembre de 2010, y convocó a un centenar de participantes, lo cual arroja un dato elocuente sobre el interés suscitado por la producción literaria de esa zona geocultural.
} 
del objeto que recorta. También aludiremos al tomo La unidad submarina que realizó Florencia Bonfiglio, aun cuando su principal labor haya estado centrada en la traducción de dos ensayos del intelectual barbadense Kamau Brathwaite. Ofrecemos un recorrido bibliográfico con la intención de dar cuenta de las líneas que siguen las investigaciones argentinas sobre el Caribe, sin poder detenernos - por razones de espacio- en todas sus particularidades ni en las distintas aristas que cada uno de estos libros explora.

\section{VOLÚMENES MONOGRÁFICOS}

Gabriela Tineo se dedica En nuestra quimera ardiente y querida a la obra narrativa del puertorriqueño Luis Rafael Sánchez, partiendo de sus textos más tempranos, cuentos aparecidos en publicaciones periódicas y también En cuerpo de camisa, de 1966, que han merecido pocas lecturas críticas -acaso por quedar a la sombra de la notoriedad que La guaracha del Macho Camacho dio al autor-, aunque la investigadora advierte en ese texto el germen de aspectos centrales en la poética estudiada. El examen de los distintos textos, que de modo muy pertinente enriquece la argumentación con el análisis de elementos retóricos y compositivos, está antecedido por un prólogo de la propia Tineo, en el cual precisa la idea de puertorriqueñidad que orienta el trabajo, a la que despoja de cualquier carga esencialista. Distintas consideraciones sociales, históricas, económicas y culturales completan el capítulo denominado "Umbrales" que enmarca la producción de Sánchez, la cual dialoga ampliamente con tal contexto cultural. El itinerario crítico que explora el corpus - que, además de los dos títulos ya mencionados, incluye La importancia de llamarse Daniel Santos- procura señalar continuidades y rupturas dentro de la producción narrativa.

También Carolina Sancholuz -docente e investigadora de la Universidad Nacional de La Plata- ancla en Puerto Rico, pero lo hace para ocuparse de la copiosa obra de Edgardo Rodríguez Juliá, cuyos textos de distintos géneros-crónica, ensayo, novela-son abordados en Mapa de una pasión caribeña. Su reflexión gira en torno de la problemática construcción identitaria a la que se refiere la autora como ficciones de puertorriqueñidad, y pone en evidencia las tensiones respecto de formulaciones anteriores que exhibían una visión de tipo homogeneizadora, como es el caso de Insularismo de Antonio Pedreira. Por ese motivo, Sancholuz elabora un cuadro de antecedentes de peso en la cultura de la isla a fin de establecer afinidades y polémicas con el autor estudiado. La primera parte incluye, además, consideraciones sobre el Caribe que contemplan y articulan distintos abordajes canónicos -regresaremos sobre este punto en el último apartado-y presenta un muy informado contexto que contribuye a reparar en las dificultades que entraña la cuestión de la identidad en Puerto Rico. Desde el punto de vista referencial, el análisis da cuenta de dos momentos asediados por Rodríguez Julia: la vida contemporánea que nutre sus crónicas -como El entierro de Cortijo y Una noche con Iris Chacón- y el

$111 \frac{\text { Revista Iberoamericana, Vol. LXXXII, Núms. 255-256, Abril-Septiembre 2016, 639-649 }}{\text { ISSN 2154-4794 (Electrónico) }}$ 
siglo XVIII revisitado y reelaborado en las novelas históricas: La renuncia del héroe Baltasar, La noche oscura del Niño Avilés y El camino de Yyaloide.

En Lecturas de la tradición en la poesía de José Lezama Lima, Daniela Chazarreta -Universidad Nacional de La Plata-se dedica al estudio de la obra poética del escritor cubano, cuyo carácter críptico suele ser destacado. Por eso, la autora emprende un trabajo de análisis textual sumamente minucioso de "Muerte de Narciso" y de Enemigo rumor, atendiendo a los diversos aspectos compositivos de la poesía -métrica, versificación, musicalidad, tópicos, recursos retóricos-y desentrañando las complejas estrategias de reescritura y apropiación de la cultura occidental. Además de la herencia cultural clásica greco-latina, el trabajo atiende a tres imaginarios de la vasta tradición occidental con los que Lezama dialoga productivamente para construir su propio linaje. Por un lado, el Siglo de Oro español, entre cuyas figuras salientes cobran particular relevancia en esta investigación Fray Luis de León, Garcilaso de la Vega, San Juan de la Cruz y Luis de Góngora. La otra zona que conforma el linaje está representada por la poesía moderna, particularmente la francesa. Paul Valéry y Charles Baudelaire son dos de los poetas en los que Chazarreta reconoce numerosos motivos y tópicos, de acuerdo con la lectura que esta crítica realiza de Le cimetière marin y Les fleurs du mal. La poesía cubana aporta asimismo una producción poética con la que dialoga Lezama: Julián del Casal. La autora encuentra sustento a su trabajo en numerosos ensayos del autor de Paradiso, entre los que cabe citar uno dedicado a Casal que es coetáneo de Enemigo rumor, aunque también se consultan otros consagrados a Valéry, Baudelaire, Poe. Justamente, estos tres autores constituyen una línea en la que Lezama busca inscribirse: se trata de la crítica literaria hecha por poetas. De todas maneras, como alerta la propia Chazarreta, el estudio no acude a los metatextos para encontrar allí una explicación causal de la poesía, sino con la intención de agregar espesor crítico a su estudio.

\section{VOLÚMENES COLECTIVOS}

Viaje y relato en Latinoamérica, coordinado por Mónica Marinone y Gabriela Tineo - ambas docentes e investigadoras de la Universidad Nacional de Mar del Plata-, contiene algunos capítulos dedicados al Caribe. No obstante, el propio armado del volumen puede leerse como una voluntad de diálogo entre distintas zonas culturales del subcontinente latinoamericano. En tal diálogo, el Caribe es ubicado como un interlocutor de privilegio, ya que el libro - tras una introducción a cargo de las coordinadoras acerca de las categorías contenidas en el título del tomo (viaje y relato)- incluye el texto del puertorriqueño Luis Rafael Sánchez "La guagua aérea”, cuya primera versión fuera publicada en 1983 en Claridad. Otras colaboraciones provenientes del Caribe son las de los también puertorriqueños Julio Ramos y Magdalena Rodríguez Castro, aunque sólo la contribución de esta última se ocupa de literatura caribeña, revisitando la

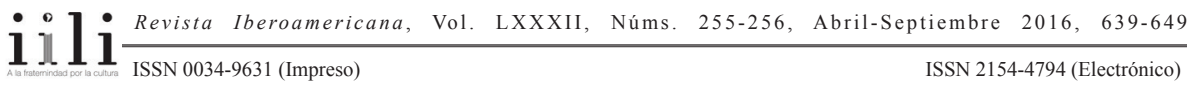


trayectoria de José Luis González. Si consideramos el Caribe en un sentido amplio que no se restringe al conjunto de islas antillanas, cabría mencionar también el trabajo del venezolano Víctor Bravo.

Es natural vincular a Alejo Carpentier con el río Orinoco, dado que es el ámbito en el que transcurre una de sus novelas más importantes: Los pasos perdidos de 1953. Marinone en "Platillos del Orinoco" regresa sobre el interés del escritor en ese accidente geográfico, pero no lo hace examinando sus novelas más consagradas, sino atendiendo a textos aparecidos en la prensa periódica que han sido descuidados por la crítica. En efecto, el trabajo realiza una lectura de cuatro artículos publicados en El Nacional en 1952, estableciendo vínculos con el imaginario forjado por otras escrituras entre las que se destaca El soberbio Orinoco de Julio Verne, autor que no tuvo una experiencia directa, sino construida a partir de diferentes lecturas.

Los capítulos firmados por Tineo y por Víctor Connena se centran en la cultura puertorriqueña. La primera realiza un estudio semiótico de documentos producidos por enviados norteamericanos a Puerto Rico tras la finalización de la Guerra Hispanoamericana. El análisis repara en discursos verbales - como las crónicas de los viajeros- y un conjunto de fotografías que procuran forjar una imagen de la isla signada por el atraso social en todos sus órdenes - desde las condiciones edilicias y la infraestructura hasta la vestimenta y la organización familiar-, a la que se contrapone la imagen de los Estados Unidos firmemente instalada en el progreso. Por su lado, Connena estudia la novela histórica - está ambientada en el siglo XVIII-El camino de Yyaloide de Edgardo Rodríguez Juliá, analizando la operatoria mediante la cual se procura revertir el solapamiento padecido por los esclavos de origen africano, cuyo rol en la historia de la isla no ha sido reconocido por el discurso historiográfico. Por ese motivo, el crítico lee en este gesto que concede voz a los grupos silenciados una rebelión en el plano discursivo en contra de una visión única del pasado.

Si bien tampoco está dedicado al Caribe de modo excluyente, se percibe que esta región cobra mayor importancia en el volumen editado, compilado y prologado por Graciela Salto -docente investigadora de la Universidad Nacional de La Pampa-, Memorias del silencio. Esta obra se divide en tres partes, de las cuales dos se centran en el Caribe. A la primera de ella nos referiremos en el último apartado por contemplar producciones no hispánicas. En cambio, la segunda sección cuenta con cinco capítulos que privilegian a la literatura cubana. El primero de ellos está a cargo de Salto, quien emprende un recorrido analítico a través de distintas elaboraciones discursivas en torno del "choteo cubano". El trabajo tiene en cuenta las tempranas formulaciones sobre esta cuestión -como las de Jorge Mañach-, aunque el estudio focaliza en las conferencias de Cintio Vitier que se reunieron en Lo cubano en la poesía y en las revisiones a cargo de Severo Sarduy. Se completa la lectura con la propuesta que Gustavo Pérez Firmat realizara en los años ochenta, lo que deriva el trabajo hacia la consideración del camp,

$111 \frac{\text { Revista Iberoamericana, Vol. LXXXII, Núms. 255-256, Abril-Septiembre 2016, 639-649 }}{\text { ISSN 2154-4794 (Electrónico) }}$ 
al tiempo que se destaca el aprovechamiento por parte de este autor de ciertos aportes de Fernando Ortiz no siempre valorados positivamente entre la intelectualidad cubana.

Los capítulos siguientes se remontan al siglo XIX, pues el Romancero cubano y un texto de José Martí constituyen sus respectivos objetos de reflexión. En primer lugar, María Pía Bruno indaga la propuesta cultural y política de Domingo del Monte, quien recupera la forma del romance desde su posición de letrado para dar cuenta en ese molde de costumbres de la sociedad cubana de las primeras décadas del siglo XIX a fin de forjar una idea de patria. La autora explica la naturaleza de este proyecto vinculándolo con distintos aspectos del contexto histórico, social, político. Por su lado, Ariela Schirmajer regresa sobre la escritura de Martí para indagar su último texto: De Cabo Haitiano a Dos Ríos. Su interés se detiene en las figuras femeninas y, a través del análisis textual, la autora advierte una construcción de la mujer cuya valoración resulta opuesta a la que trasuntan los Versos sencillos. La lectura contrastiva se completa con la figura de Lucy Parsons -viuda de uno de los anarquistas condenados a muerte en 1886 en Chicago-, a la cual el autor cubano dedicara página de sus Escenas norteamericanas.

Se produce un salto temporal en lo referido a los asuntos tratados en los dos capítulos siguientes, los cuales cierran la sección del tomo consagrada a Cuba. El interés de María Virginia González es convocado por Ella escribía poscrítica de Margarita Mateo Palmer, mediante la exploración del cruce de géneros discursivos constitutivo de este texto que alterna capítulos de tipo reflexivo con otros de corte ficcional. Así, el trabajo indaga las distintas modulaciones del ensayo que participan en la escritura, teniendo especialmente en cuenta el gesto transgresor de una mujer al hacer uso de un género mucho más frecuentado por sus colegas varones. También María Fernanda Pampín privilegia, en el capítulo a su cargo, un texto correspondiente al denominado Período Especial, al exponer su lectura de Inventario secreto de La Habana de Abilio Estévez, quien escribe esta obra en España a partir de un encargo editorial que le solicitaba una suerte de guía de viajes. Ese proyecto viró hacia esta novela que Pampín asedia desde distintos ángulos, como son las continuidades y los desvíos respecto del relato de viajes canónico, así como los procesos de construcción ficcional.

Ínsulas y poéticas. Figuras literarias en el Caribe es otro libro a cargo de Salto, aunque éste está enteramente dedicado a las literaturas y las culturas del Mar Caribe. Los once trabajos reunidos se organizan en tres secciones. La primera de ellas se denomina "Poéticas de la memoria insular" y se inaugura con una reflexión de Mónica Bernabé que circula a través de distintas problemáticas centrales de la región, de las cuales un punto privilegiado es el concepto de transculturación acuñado por el cubano Ferando Ortiz, así como sus posibilidades y sus proyecciones en la crítica cultural latinoamericana. A continuación, Tineo realiza una lectura de La noche oscura del Niño Avilés de Rodríguez Juliá que pone en evidencia la construcción de una contraversión de la historia oficial, en tanto la novela asume una actitud reparadora o, como prefiere

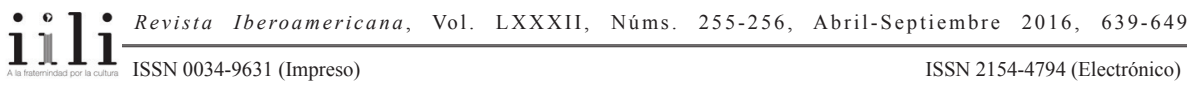


la autora, una operación contrafactual, a través de una composición novelesca que combina fuentes verídicas e inventadas. También Rodríguez Juliá es revisitado por Sancholuz, quien en esta oportunidad se centra en el volumen de crónicas Caribeños, con el propósito de reconocer vínculos entre la perspectiva del puertorriqueño y las de otros autores que asumen el desafío de pensar el Caribe como un conjunto (Antonio Benítez Rojo, Arcadio Díaz Quiñoñes, Édouard Glissant y Ana Pizarro). La sección se cierra con la contribución de Elsa Noya, quien reconstruye y analiza un debate que tuvo lugar en revistas culturales de Puerto Rico en los años noventa y que fue iniciado por las intervenciones desde la prisión en los Estados Unidos de Elizam Escobar. La polémica cuenta con interlocutores notables como John Beverley y Juan Duchesne-Winter.

La segunda sección, "Poéticas de la lengua", comienza con un trabajo de Celina Manzoni dedicado al cubano Guillermo Rosales, cuya instalación en Miami permite plantear la cuestión del bilingüismo que, según la lectura que esta especialista expone de Boarding Home, instala pugnas entre el inglés y el español, lo que redundaría en una tensión lingüística y cultural. En segundo lugar, Sonia Bertón reconsidera la noción de exilio desde distintos ángulos teóricos y a partir de las condiciones específicas en lo que concierne a Severo Sarduy y, desde ese marco, se detiene en la novela Maitreya, con particular atención a lo corporal, a la sexualidad y al lenguaje. El tercer capítulo de la sección está a cargo de Denise León, quien se aproxima al poemario Ánima (2002) del poeta nacido en Cuba José Kozer mediante cinco notas que están antecedidas por una presentación del autor y destacando su herencia judía y su condición de exiliado.

Finalmente, la sección "Poéticas de la tradición" cuenta con un extenso estudio de Alejandra Mailhe acerca de los cambios en la obra de Fernando Ortiz previa al Contrapunteo cubano del tabaco y el azúcar en lo referido a las visiones sobre la cultura negra, de manera tal que se ponen en jaque las divisiones tajantes entre las etapas positivista y culturalista en la vasta producción del antropólogo cubano. Por su parte, María Guadalupe Silva transita por los textos contenidos en el tomo Cercanía de Lezama Lima, publicado en 1986 a cargo de Carlos Espinosa, con la finalidad de identificar algunas imágenes recurrentes del autor de Paradiso, como son la del Maestro, el Poeta, la Víctima, el Patriota y el "Señor Barroco". El siguiente capítulo, firmado por Carmen Perilli, aborda dos novelas del cubano Leonardo Pardura Fuentes que presentan ficciones de autor; mientras La novela de mi vida retoma la figura de José María Heredia, Adiós Hemingway se interesa por el autor norteamericano. La propia editora del volumen es quien está cargo del capítulo final. Allí, Salto analiza tonos y voces del siglo XIX cubano -José María Heredia, José Jacinto Milanés, Cirilo Villaverde- y su resignificación en el marco de discusiones actuales, reflexionando sobre la idea de archivo con sus límites y zonas de exclusión. 


\section{Un diálogo entre el Caribe y el Cono Sur}

Sin duda las revistas Orígenes y Sur se erigen como dos proyectos culturales latinoamericanos de muy significativa relevancia en el siglo XX. Entre los numerosos aspectos que diferencian a estas publicaciones podrían citarse, entre otras, el repertorio de colaboradores o las condiciones económicas que, al determinar tiradas muy superiores en el caso argentino, redundaban asimismo en la capacidad de distribución de los ejemplares. No es menor la diferencia que supone la duración alcanzada, ya que la publicación argentina ostenta una dilatada existencia que se extiende desde 1931 hasta la muerte de su directora, Victoria Ocampo, en 1979 - aunque continuaron publicándose de modo errático algunos números especiales, muchos de ellos con carácter de homenaje-, mientras que la cubana apenas tuvo lugar entre 1944 y 1956. De manera que los doce años de vida de Orígenes fueron contemporáneos a un tramo de la trayectoria de Sur. Nancy Calomarde en su libro El diálogo oblicuo realiza un estudio que pone en evidencia distintas relaciones entre ambas publicaciones, las cuales no habían sido advertidas por los numerosos estudios particulares dedicados a las revistas por separado. Cabe destacar que el estudio no desatiende la heterogeneidad en el interior de cada proyecto, gracias a lo cual la reflexión se enriquece por la consideración de las tensiones entre los miembros.

De manera tal que ese diálogo resulta de la meritoria reconstrucción de la investigadora, quien diseña recorridos a través de diversas formas discursivas, en tanto se detiene en textos que podrían considerarse de primer orden -cuentos, ensayos- pero también indaga materiales menos transitados por la crítica, como es el caso de las reseñas, de la correspondencia, de notas, lo que autoriza plantear la oblicuidad del vínculo, advirtiéndose mayor atención de parte de los cubanos respecto de lo que ocurría en Buenos Aires. Así, Calomarde emprende una lectura contrastiva de las reseñas que Jorge Luis Borges y CintioVitier dieron a conocer en sus respectivas revistas sobre Las ratas del argentino José Bianco. Asimismo, el trabajo repara en la lectura que Fina García Marruz realiza de Espacios métricos de Silvina Ocampo. Estos recortes permiten echar luz sobre el criterio que los sustenta, que Calomarde relaciona con una imagen especular que los cubanos buscaban de sí mismos.

Otro aspecto importante que releva esta investigación se encuentra en lo que la autora denomina repertorios comunes a las dos revistas. El filósofo español José Ortega y Gasset es una figura insoslayable para ambas empresas culturales, si bien su abordaje es divergente, puesto que Sur se aproxima a su obra desde marcos disciplinares precisos -el ensayo de corte más académico era frecuente en la revista de Ocampo- mientras que Orígenes lo recupera como una totalidad, a la manera de un letrado tradicional. Eduardo Mallea y Pedro Henríquez Ureña también integran esos repertorios comunes. Este último fue un impulsor de la revista cubana por el vínculo con uno de sus directores, José Rodríguez Feo, y una personalidad de innegable centralidad en la revista argentina, 
de lo que es prueba el homenaje que se le rinde tras su muerte a cargo de conspicuos colaboradores.

Los últimos capítulos del libro están consagrados al escritor cubano Virgilio Piñera, cuya residencia en Buenos Aires diseña una línea del diálogo entre las publicaciones, dado que procuró establecer un nexo que redundara en colaboraciones argentinas en Orígenes y en la inclusión de sus propios textos en Sur. Calomarde, entonces, rastrea gestiones y proyectos que emprende Piñera-con resultados dispares-así como los lazos que logró trabar con personalidades como Borges, Sábato y el polaco Gombrowicz.

\section{LA INCIPIENTE AMPLIACIÓN DEL HORIZONTE CRÍTICO}

La heterogeneidad de la región caribeña se explica, entre otros aspectos, por la variedad de lenguas europeas empleadas, puesto que además del español se registran producciones literarias en francés, en inglés y en holandés. Esta variedad lingüística obedece históricamente a la empresa colonial, que en la actualidad -a pesar de los numerosos Estados que alcanzaron la independencia durante el siglo XX, especialmente durante la segunda mitad-no ha disuelto por completo el lazo con las metrópolis, ya que distintas islas forman parte de Estados europeos o de los Estados Unidos, bajo diversos estatutos político-administrativos. Junto a las lenguas europeas $-\mathrm{y}$ generalmente en tensión- existen lenguas vernáculas surgidas en el propio contexto de la explotación colonial, las cuales suelen combinar elementos de lenguas metropolitanas con otros provenientes de lenguas africanas, amerindias o bien aportadas por otros grupos migratorios, como los asiáticos. Nos referimos al créole en el ámbito francófono, a los pidgin en el anglófono, al papiamento en islas de habla holandesa y al sranan en Surinam.

El recorrido que hemos realizado a través de los trabajos críticos sobre literaturas caribeñas no parece tener en cuenta esta variedad lingüística, en tanto la mayoría de los trabajos atienden a autores de origen puertorriqueño y cubano, mientras que las literaturas de los otros bloques lingüísticos parecen obliteradas. Ahora bien, es cierto que -más allá de posibles juicios de valor- la barrera lingüística supone un obstáculo para la crítica literaria emprendida desde el ámbito de lengua española, como también es evidente que distintas condiciones de producción auspician una mayor circulación de los textos provenientes de Cuba y de Puerto Rico, lo cual no ocurre con la literatura de República Dominicana, a pesar de ser también un país hispanoparlante. No obstante, al leer los trabajos críticos de modo más detenido es posible observar una incipiente tendencia hacia una apertura de la mirada, que incluso cuando se trabaja sobre textos del Caribe hispánico tiende a considerar el conjunto caribeño, a través de ciertas figuras salientes.

En tal sentido, cabe destacar que al momento de considerar la idea de insularismo como la entiende Lezama Lima, Chazarreta despliega un panorama que registra las posiciones de intelectuales que abordaron esa noción: Antonio Pedreira, Rodríguez Juliá, pero también el martiniqueño Édouard Glissant, atendiendo especialmente a su idea de

$111 \frac{\text { Revista Iberoamericana, Vol. LXXXII, Núms. 255-256, Abril-Septiembre 2016, 639-649 }}{\text { ISSN 2154-4794 (Electrónico) }}$ 
créolisation expuesta en Introduction à une poétique du divers. Por su lado, Sancholuz también recoge los aportes de Glissant, pero ya no para considerar contrastivamente un aspecto puntual del objeto de estudio, sino que se ocupa de este autor, junto a Benítez Rojo y Ana Pizarro, en el capítulo inicial de su libro Mapa de una pasión caribeña, procurando poner en diálogo las tres propuestas teórico-críticas que intentan considerar el conjunto caribeño a partir de dinámicas y núcleos comunes. En la misma línea se ubica el trabajo de esta experta incluido en el volumen de Salto Ínsulas y poéticas, donde atiende al volumen Caribeños, cuya misma temática reenvía hacia otras zonas lingüísticas y culturales.

En el mismo tomo Ínsulas y poéticas, las contribuciones de Bernabé y de Mailhe apuntan a fracturar la insularidad de sus objetos al orientar zonas de sus trabajos hacia una lectura contrastiva con discursos del Caribe francófono. Además de los aportes que suponen las reflexiones de Glissant, Bernabé emparienta el trabajo de transculturación sobre el lenguaje que realiza el martiniqueño Aimé Césaire en Cahier d'un retour au pays natal con aquel emprendido por Luis Palés Matos en Tuntún de pasa y grifería. En cuanto a Mailhe, cabe destacar su lectura de la trayectoria bibliográfica de Ortiz enriquecida por la comparación que realiza con la clásica obra etnográfica del haitiano Jean Price-Mars, Ainsi parla l'onlce. En su análisis, esta investigadora revela un desencuentro entre los objetivos perseguidos de manera explícita por el haitiano y su concreción en el discurso ensayístico.

Como adelantamos, la primera sección de Memorias del silencio se aventura a incorporar al repertorio crítico producciones provenientes del Caribe no hispánico. Tal tarea se logra mediante la inclusión de un texto editado por Ineke Phaf-Rheinberger que ofrece un diálogo entre Édouard Glissant y Kamau Brathwaite en la versión castellana de la investigadora chilena Carolina Benavente Morales, quien es asimismo responsable de un trabajo en el que reflexiona sobre su experiencia como traductora de ese texto. También desde Chile se suma el aporte de Irmtrud Köning, cuya colaboración ofrece una aproximación a la obra dramática de Aimé Césaire al destacar la relación de esta etapa en su producción-que tuvo lugar en la década de 1960-con condiciones políticas, signadas principalmente por la descolonización de numerosos países africanos, así como de algunos estados de las Antillas. Por último, María Alejandra Olivares suma su trabajo dedicado al Caribe de expresión inglesa con centro en las formas breves de la escritora Jamaica Kincaid y estableciendo un diálogo con Michael Thomas Martin.

También el Caribe anglófono es considerado por Florencia Bonfiglio, quien asume la necesidad de llevar adelante la traducción como estrategia para superar las barreras que mantienen a las producciones caribeñas no hispánicas fuera del panorama crítico argentino. En tal sentido, cabe destacar que, en el volumen La unidad submarina, Bonfiglio traduce dos ensayos emblemáticos de Kamau Brathwaite y, asimismo, es responsable de un extenso estudio preliminar que traza los rasgos más salientes de la trayectoria

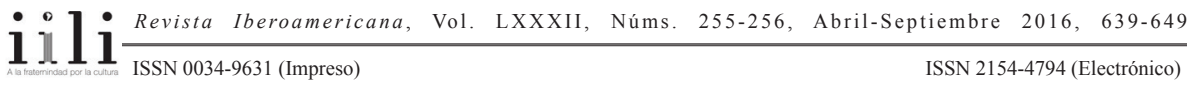


intelectual del autor barbadense y analiza conceptos centrales de su pensamiento, como es el caso de la idea de lenguaje-nación.

El trayecto bibliográfico que hemos trazado - el cual se ha visto obligado a dejar de lado distintos matices de cada trabajo- confirma, en primer lugar, la vitalidad de los estudios dedicados a las literaturas caribeñas en el ámbito universitario argentino. ${ }^{2} \mathrm{La}$ novela parece un género especialmente privilegiado en los diversos proyectos críticos, aunque también el ensayo, la crónica y, en menor medida la poesía, se constituyen en objetos de investigación. Sin duda una tradición más asentada en la Argentina redunda en el interés predominante por las literaturas cubana y puertorriqueña. No obstante, tales producciones van siendo abordadas desde perspectivas que conciben, a pesar de su heterogeneidad, la unidad del Caribe en cuanto a una serie de rasgos, dinámicas y núcleos comunes. En ese sentido, la particular atención a alguna zona de la literatura en lengua española no supone el completo solapamiento de otras zonas Caribeñas, ya que las pesquisas pueden recibir aportes de otros bloques lingüísticos, como es el caso del pensamiento de Glissant. Este gesto de apertura se complementa con estudios que avanzan paulatinamente sobre literaturas en francés y en inglés como tema central de las indagaciones. La tarea crítica acerca de esas zonas poco transitadas entre nosotros hasta la fecha se ve conducida no solamente al estudio de los textos y de las culturas de las que emergen, sino también a la traducción al español como estrategia para alentar su incorporación al horizonte crítico argentino.

\section{BiBLIOGRAFÍA}

Basile, Teresa, comp. La vigilia cubana: sobre Antonio José Ponte. Rosario: Beatriz Viterbo, 2009.

Brathwaite, Kamau. La unidad submarina. Ensayos caribeños. Traducción, selección y prólogo Florencia Bonfiglio. Buenos Aires: Katatay, 2010.

Calomarde, Nancy. El diálogo oblicuo. Orígenes y Sur: fragmentos de una escena de lectura latinoamericana (1944-1956). Córdoba: Alción, 2010.

Chazarreta, Daniela E. Lecturas de la tradición en la poesía de José Lezama Lima. Quilmes: Caligrafías, 2012. CD-ROM.

Marinone, Mónica y Gabriela Tineo, eds. Viaje y relato en Latinoamérica. Buenos Aires: Katatay, 2010.

Noya, Elsa. Leer la patria. Estudios y reflexiones sobre escrituras puertorriqueñas. Córdoba: Alción, 2004.

2 Debido a que hemos acotado esta reflexión a los textos aparecidos entre 2010 y 2012 no hemos analizado un trabajo anterior de Elsa Noya: Leer la patria. Estudios y reflexiones sobre escrituras puertorriqueñas (2004). También cabe citar el volumen compilado por Teresa Basile La vigilia cubana: sobre Antonio José Ponte (2009). 
Salto, Graciela, ed. y comp. Memorias del silencio. Literaturas en el Caribe y en Centroamérica. Buenos Aires: Corregidor, 2010.

Salto, Graciela, ed. Ínsulas y poéticas. Figuras literarias en el Caribe. Buenos Aires: Biblos, 2012.

Sancholuz, Carolina. Mapa de una pasión caribeña. Lecturas sobre Edgardo Rodríguez Juliá. Buenos Aires: Dunken, 2010.

Tineo, Gabriela. En nuestra quimera ardiente y querida. Refundar la puertorriqueñidad en Luis Rafael Sánchez. La Plata: EDULP, 2010. 
